contracted and the discs pale. There was no deafness and no tinnitus, and though he said he was giddy on sitting up, there was no true aural vertigo.

He was sent up to hospital immediately, and on admission was given amyl nitrite inhalation and sodium nitrite gr. ij. Mr. R. R. James saw him two hours later and reported, "The arteries are normal. L.O.D. slight pallor inner side; R.O.D. normal. Pupils mid-dilated ; right flickers to strong light, left inactive to light."

Recovery was very rapid. In the evening he could distinguish windows, shadows, etc., and by the following morning his sight was apparently normal. Two days after taking the quinine his visual fields showed no contraction, and his fundi were normal. Nor was his sight in any way deficient two months later.

The Wassermann reaction was negative.

The taking of quinine was confirmed by finding it in the urine.

The interesting features of this case were the absence of auditory symptoms and the complete recovery so soon after treatment by the nitrites.

We are indebted to Dr. F. Golla and to Mr. R. R. James for permission to publish this case.

\title{
AN UNUSUAL CASE OF PERFORATING WOUND OF THE CORNEA
}

BY

Charles Killick, M.D., F.R.C.S.

HON. OPHTHALMIC SURGEON, ROYAL EYE AND EAR HOSPITAL, BRADFORD

Mrs. B., age 31, was mending the fire on January 27,1921 , when, through some mishap, the poker slipped and fractured the left lens of her spectacles. Realising that something serious had happened to her left eye she at once saw Dr. Shaw, of Cleckheaton, who sent her to see me without delay.

On examination two separate perforating wounds of the cornea were present; the one lacerated, situated in the two o'clock position, was in the form of a triangular flap of cornea attached by its base to the limbus and extending into the cornea downwards and slightly outwards for about three millimetres. This tongueshaped flap was freely movable, projected above the corneal surface and looked much like a fragment of glass; the iris was freely exposed, but was not protruding from the wound. The second perforation was exactly opposite the first, and was placed at the inferior margin of the cornea, it traversed the limbus at right angles for about two millimetres and was occupied by prolapsed iris. Fortunately the ciliary.body, lens and vitreous were intact. As a 
further complication the conjunctiva in the vicinity of the upper wound was extensively contaminated by coal dust.

Although any attempt to save the eye appeared under the circumstances to be doomed to failure, no harm could be done in making the effort, and the first thing therefore was to excise all prolapsed iris. The next step was to dissect up the conjunctiva all round the globe, and having sufficiently undermined it to cover the whole cornea with the flap thus formed, bringing the cut edges together without any tension with three mattress sutures. Atropin ointment was finally introduced, and the eyes closed by a binocular pad. The operation was done under cocaine, and the patient's behaviour was exemplary. Little or no reaction followed, the eye was dressed once daily, and, in addition to the atropin, drops of acriflavine $(1 / 1,500)$ were instilled. Recovery was uneventful, the stitches gradually came away, the conjunctiva resumed its normal position, and on February 8 a single pad was substituted for the binocular, and the patient allowed up. Two days afterwards dark glasses were ordered.

On February 11, i.e., twelve days after the accident, the condition was as follows :-Right eye healthy, vision $6 / 18$ with -1.00 D. sph. 6/6. Left eye, lens clear, fundus normal, pupil fully. dilated, eye free from redness. The inferior wound is healed, the upper cut edge of the iris being, however, adherent to the cornea at this point. The superior wound is entirely covered by adherent conjunctiva, which extends on to the cornea as far as the original apex of the lacerated flap. This wound also is perfectly healed and free from redness. Above it is a crescent-shaped area of conjunctiva heavily peppered with granules of coal dust. The iris is adherent to the cornea in the neighbourhood of the wound, but is not incarcerated. On inspecting the eye on this occasion quite a large fragment of glass, about $3 \mathrm{~mm}$. long by $1 \mathrm{~mm}$. broad, was found free in the lower cul-de-sac. The patient had complained of slight discomfort for a day or two, but nothing had been seen to account for it. She was discharged from hospital on February 14.

I saw her again on March 9 last. The eye had entirely recovered. The pupil was somewhat pear-shaped, with its apex down and out. Vision, with $-2.00 \mathrm{D}$. cyl. ax. $95^{\circ}$ was $6 / 6(3)$.

The most interesting feature of the above case lies in the fact that two separate perforating wounds of the cornea were inflicted, which is unique so far as my own personal experience goes, and one of these wounds was of such a serious character as to threaten the eye with total loss. The amount of vision restored, too, is, I think, very exceptional.

The successful result may be attributed, in my opinion, to the following factors :-(1) The lens, ciliary body and vitreous were intact; ( 2 ) the wounds were promptly protected by a conjunctival 
dressing ; and (3) it is possible that the acriflavine drops, as recommended by Lawson, played some part in keeping the eye aseptic, because, as has been pointed out, the conjunctiva was extensively soiled.

\section{REFERENCE}

Lawson, A.-Trans. Ophth. Soc., 1919.

\section{ANNOTATIONS}

\section{Report on Miners' Nystagmus}

We have been furnished with an advance copy of the First Report of the Miners' Nystagmus Committee, which was appointed in 1920 by the Medical Research Council at the request of the Home Office, and upon the recommendation of the Miners' Lamps Committee, to investigate the Cause and Means of Prevention of Miners' Nystagmus. The present Report comprises the reports of Dr. T. Lister Llewellyn and Dr. W. H. R. Rivers, a further report by Mr. G. H. Pooley on the relation of errors of refraction to miners' nystagmus being in course of preparation. Dr. Llewellyn has clinically examined 2,000 cases from the different coalfields of the Kingdom, while the psycho-neurotic factors have been studied by Dr. W. H. Eddison and embodied in Dr. Rivers' report. The working conditions have been investigated, and photo- metric tests of great importance have been made by Dr. Llewellyn.

It is interesting to learn that defective illumination, which has lately tended to displace other theories of causation, is adopted by this Committee as the essential factor in the causation of the disease. Other factors, such as position, alcoholism, hereditary predisposition and errors of refraction are considered to be merely of secondary importance. The causes of this defective illumination are partly the initial low illuminating power of safety lamps, partly the gradual failure of batteries, the accumulation of coal dust about the lamps, the distance of the lamps from the work, and so forth.

The Committee find that workers at the coal face are more affected (81.5 per cent. of all the cases) than other underground workers, due to the unrelieved blackness of the coal and the greater need for accurate vision. Of the large proportion of miners who show signs of nystagmus, only a small proportion become incapacitated for work underground. The Committee naturally recommend that various steps should be taken to improve the illumination not only by increasing the power of the lamps, but also by increasing the amount of reflected light by whitewashing and otherwise treating parts of the pit other than the actual coal 